\title{
Los migrantes colombianos en la prensa colombiana: una lectura de género 1990-2006'
}

\section{The Colombian Migrants in the Colombian Press: A Lecture of Gender: 1990-2006}

\section{Os migrantes colombianos na imprensa colombiana: uma leitura de gênero 1990-2006}

\section{Victoria Elena Bazurto Botero ${ }^{2}$}

Investigadora en la Universidad de Nantes, Nantes, Francia

vickybazurto@gmail.com

Recibido: $29 / 10 / 14$ Aprobado: 14/04/15

$1 \quad$ Este artículo forma parte de una investigación que se inscribe dentro de la tesis doctoral titulada Imagen(es) y representación(es) de los migrantes colombianos: análisis comparado de la prensa colombiana y la prensa española 1990 - 2006, inscrita en la Universidad de Nantes (Francia) bajo la dirección de Pilar Martínez-Vasseur PhD., en cotutela con la Universidad Externado de Colombia, bajo la dirección de Milena Gómez Kopp, PhD.

2 Licenciada en Lenguas Modernas, con énfasis en lingüística y literatura hispanoamericana, Master en Estudios Hispánicos y Master en Estudios Culturales. 


\title{
Resumen
}

Este artículo tiene como objetivo identificar las representaciones creadas a través del discurso de los periódicos El Tiempo y El Espectador, en torno a las emigrantes colombianas a España. Para tal fin, se analizaron los artículos de estos rotativos desde el 1 de enero de 1990 hasta el 31 de diciembre de 2006. A pesar de reconocer la importancia de las mujeres dentro del fenómeno migratorio colombiano, persiste un discurso no adaptado en los periódicos en el que predomina el genérico masculino. Por otro lado, las representaciones culturales positivas que les son atribuidas resultan minoritarias, frente a aquellas que les designan como responsables de la desestructuración familiar y en tanto que víctimas de la trata y del tráfico de personas.

Palabras clave: migración colombiana; género; representación; España.

\begin{abstract}
The following article has the goal of identify the representations created through the discourse of the newspapers El Tiempo and El Espectador around the Colombian women emigrating to Spain. To that end, the articles published in these newspapers from January 1st, 1990 to December 31 ${ }^{\text {st }}, 2006$ were analyzed. Despite recognizing the importance of women within the Colombian migration phenomenon, an inadequate discourse remains in the newspapers in which predominate the generic male form. Furthermore, the positive cultural representations given to them appear to be in very low numbers as opposed to those that designate them as responsible of family breakdown and as victims of human trafficking and people smuggling.
\end{abstract}

Keywords: Colombian migration; gender; representation; Spain.

\section{Resumo}

Este artigo tem como objetivo identificar as representações sobre as migrantes colombianas na Espanha, através do discurso dos jornais El Tiempo e El Espectador. Nessa ordem, se analisaram os artigos a partir de 01 de janeiro de 1990 até 31 de dezembro de 2006. Apesar de reconhecer a importância das mulheres dentro do fenômeno migratório colombiano, persiste um discurso não adaptado nos jornais, no qual predomina o masculino genérico. Por outro lado, as representações culturais positivas que lhes são atribuídas são menores perante aquelas que as designam como responsáveis da desestruturação familiar, e como vítimas do tráfico de pessoas.

Palavras-chave: migração colombiana; gênero, representação, Espanha.

Este trabajo está bajo la licencia Creative Commons Attribution 3.0 


\section{Introducción}

"La diferencia de género se inscribe en los discursos de alteridad, de definición del otro en la formación de subjetividades individuales y colectivas o en su expresión como identidades" (Nash 2005, 46). Dentro de este proceso de definición, encontramos que los medios de comunicación desempeñan un papel importante en la forma de interpretar, conocer e identificar al otro. En este sentido, la prensa determina a través de su discurso quiénes serán representados y cuáles serán los significados que se les asocien.

Partiendo de esta primera aproximación, el objetivo de este artículo es analizar la imagen y la representación de las mujeres migrantes colombianas en España, a través del discurso creado por la prensa colombiana durante el período 1990-2006. Para tal fin he seleccionado dos periódicos, El Tiempo y El Espectador, partiendo de tres aspectos: la difusión nacional, su fuerte presencia e influencia en la opinión pública colombiana (Observatorio de Medios 2009) y el número de tiradas anuales.

El período en el que se inscribe este estudio corresponde a un momento decisivo para la sociedad colombiana. Desde el punto de vista político, se plantea un cambio de Constitución en 1991 y con este la apertura no solamente democrática, sino también política y económica en el país. Las consecuencias de la reestructuración del modelo económico serán, entre otras:

\footnotetext{
La quiebra de miles de empresas que no lograron hacer frente a los bajos precios de los productos importados que entraron en el mercado colombiano; la reducción del tamaño del Estado y su participación en programas de bienestar social; los recortes en la nómina de empleados oficiales; a lo que se aúna el colapso de los precios internacionales del café principal divisa del país la mayor parte del siglo pasado" (Guarnizo 2008,14-15).
}

Esta crisis, entre otras razones, servirá como factor de expulsión de miles de colombianos, en búsqueda de mejores condiciones de vida y de oportunidades laborales, iniciándose así un nuevo período emigratorio (Aparicio y Giménez 2003; Garay y Medina 2007) que, a diferencia de los movimientos registrados desde los años 1960, dirigidos principalmente a Estados Unidos, Venezuela y Ecuador (Guarnizo 2008, 13-14), presenta una diversificación en términos de los destinos, siendo España uno de los más importantes; un aumento en el número de personas que salen de Colombia de diferentes estratos económicos, y una progresiva presencia de mujeres en los flujos migratorios.

Es decir, que si tradicionalmente eran los hombres quienes migraban y reagrupaban sus familias, en esta época serán mayoritariamente las mujeres las que asumirán este rol. Hecho que está "íntimamente relacionado con la demanda de trabajadoras inmigrantes en el servicio doméstico [en España]" (Solé y Parella 2006, 59) "debido a los cambios al interior de la familia española, por la mayor participación de las mujeres nacionales en el mercado de trabajo" (Rivas y Gonzálvez 2009, 66). De esta forma, para las mujeres colombianas, "ante la existencia de una estructura de género desigual y una baja remuneración en origen” (Garay y Medina 2007, 69-70), la migración se perfila como una estrategia no solamente económica y familiar, sino también en algunos casos, de emancipación. 
Para determinar la imagen y la representación de las mujeres colombianas que emigraron a España, se procedió a la consulta de los periódicos seleccionados desde el primero de enero de 1990, hasta el 31 de diciembre de 2006 ${ }^{3}$. Esto arrojó como resultado la presencia de 565 artículos, de los cuales 143 hacen referencia directa a la emigración hacia España. Una vez identificados los artículos, se procedió al análisis temático de los mismos, con el fin de determinar las entradas ${ }^{4}$ más recurrentes durante todo el período estudiado.

De los 143 artículos, se pudo establecer que 23 de estos dan la palabra a los migrantes, y solo 19 hacen referencia directa a mujeres. Esto demuestra el acceso reducido a la palabra que tienen los emigrantes, y la poca representatividad de las mujeres en relación con la información que circula en torno a la emigración hacia España. Sin embargo, es de resaltar que los artículos en los que se citan testimonios, son las mujeres las que aparecen como actoras decisivas de este desplazamiento, que para 2005 concierne a más de tres millones de personas colombianas (DANE 2008). Empero, y como veremos a lo largo de este artículo, aun siendo las mujeres las portavoces del proceso migratorio, asistimos a un discurso no adaptado en el que predomina como norma el genérico masculino.

Los tópicos que a continuación presentamos surgen como los más recurrentes al momento de hacer referencia a las mujeres emigrantes. Entre ellos, la mujer como sinónimo de fuerza y de iniciativa (1); seguido de la mujer doblemente marginada, tanto por su condición de indocumentada como por su condición de víctima de trata y tráfico de personas, tema este que será uno de los más evocados (2); y finalmente, el rol que se le designa como miembro de la familia y la responsabilidad que se le adjudica en el funcionamiento de la misma, una vez en marcha el proceso migratorio (3).

\section{La mujer emprendedora}

Los artículos que hacen referencia a la diáspora colombiana permiten identificar la feminización de los flujos migratorios, gracias a los perfiles sociodemográficos que en estos se establecen. Pocos son los titulares que lo enuncian explícitamente, por lo cual, el acceso a esta realidad se hace a través de la información descrita en el artículo, dificultando así la visibilidad de las mujeres en el discurso global sobre las migraciones. En este contexto se destaca su rol como protagonistas del proyecto migratorio. De ahí que una de las percepciones que se tenga con respecto a ellas, sea justamente su capacidad de emprender, tal como sugiere la expresión utilizada en el titular Echadas pa' lante, de El Tiempo (03 de diciembre, 1993). El artículo menciona por primera vez entre 1990-2006, la presencia de las mujeres colombianas en España resaltando su participación en el programa Mujer Inmigrante, creado por la Federación de mujeres progresistas de España; con el objetivo de "proporcionar la igualdad de derechos de

3 Para esta investigación se consultaron, del periódico El Tiempo, 1.095 ejemplares en formato impreso y 990 artículos en formato digital, encontrados a través del motor de búsqueda disponible en su página web. Del periódico El Espectador, se consultaron 4.126 ejemplares en formato impreso. Los ejemplares impresos de los dos periódicos fueron consultados en los archivos de la Biblioteca Luis Ángel Arango de Bogotá.

4 Término prestado a la gramática, que designa los temas presentes en un artículo. 
oportunidades y erradicar la doble discriminación que sufren: de un lado, por ser mujer y, del otro, por ser migrantes" (El Tiempo, 03 de diciembre, 1993). La presencia de las emigrantes colombianas en este programa es reveladora de las dificultades que ya para ese entonces obstaculizaban su instalación en dicho país.

Los testimonios recogidos por la prensa permiten identificar las razones que motivan la emigración de estas mujeres, así como las trayectorias que han seguido una vez iniciado el proceso migratorio. Estos revelan que la migración, más que una decisión individual, forma parte de una estrategia familiar, en la que cada miembro tiene un rol importante y es concernido de manera directa o indirecta.

Llevaba dos años desempleada cuando escuché el anuncio del Sena. Necesitaban gente con experiencia en cocina, mesa y bar para trabajar en España. No lo pensé dos veces ([María] "Con los sueños en la maleta”, El Tiempo, 26 de enero, 2003).

A Madrid llegó por consejo de dos hermanos que ya vivían en la capital española y con la misma meta (...) de quienes abandonan su país por necesidad: salir adelante y ayudar a mi familia ([Rubiela] "Cuando la dicha es volver", El Tiempo, 05 de noviembre, 2003).

En el caso de María y Rubiela, la migración es un medio para salir adelante y ayudar a su familia. Para Yolanda, es la posibilidad de recomenzar, ante la falta de proyecto profesional y de opciones en Colombia.

Ayer fui a tres sitios, pero (...) sin papeles es imposible (...). Yo trabajaba en una sucursal bancaria, al sur de Bogotá, (...). Cuando comenzaron a recortar gente en la empresa, (...) negocié mi salida y con esa plata me compré el pasaje, (...) traje con qué vivir mientras tenía suerte. Pero hasta ahora nada ([Yolanda] "El lejano sueño español", El Espectador, 25 de junio, 2000).

La migración puede ser igualmente una forma de alcanzar la independencia y emanciparse.

Un día le dije a mi mamá que yo quería independizarme. Me propuso que me fuera para Estados Unidos donde una tía yo le dije que no, que independencia era independencia y monté viaje a España ([Mónica] "El lejano sueño español", El Espectador, 25 de junio, 2000).

O finalmente, producto de una situación extrema que obliga al desplazamiento.

Mi esposo (...) se metió en el narcotráfico (...) A la cuarta [vez de traer droga a España] (...) lo detuvieron en el aeropuerto. Tiene una condena de casi diez años. (...) Me endeudé y me vine ([Martha] "El lejano sueño español", El Espectador, 25 de junio, 2000).

Estos testimonios indican igualmente que se trata de mujeres que migran solas y que lo hacen, en algunos casos, gracias a las cadenas migratorias de las que forman parte la familia ya en destino, o los amigos que aconsejan y/o apoyan para poder organizar el proyecto migratorio. Por otro lado, se muestra que aquellas que llegaron a España directamente se encuentran sin papeles y que no 
necesariamente cuentan con muchos recursos, ya que deben recurrir a la venta de sus bienes, a préstamos, o aun a los ahorros por liquidación para poder viajar. Situación completamente diferente para María, que emigró en 2003, dentro de los contingentes de trabajadores colombianos definidos a través de los acuerdos de migración laboral ${ }^{5}$, que permiten salir del país con los documentos en regla y un contrato de trabajo firmado antes de llegar a España.

La emigración de las mujeres, particularmente aquellas que son madres, trae consigo una organización necesaria para el cuidado y la educación de los hijos que se quedan en origen, que forma parte de la reconfiguración de roles dentro del proyecto migratorio como estrategia familiar.

Sus hijas se fueron a España en los últimos cuatro años (...). Hoy, Rocío cuida tres nietos, para lo que le giran casi dos millones de pesos mensuales, y sus hijas disfrutan de comodidades que no tuvieron de niñas ([Rocío Balanta] "Arrancó censo de migración y remesas", El Tiempo, 03 de agosto, 2004).

Este caso es representativo de una de las estrategias más empleadas, ya que una vez se plantea la necesidad de migrar, "la abuela se erige como la principal [aunque no la única] cuidadora de los hijos, en tanto depositaria de la confianza materna para suplir su papel" (Rivas y Gonzálvez 2009, 121).

La platica me alcanza para hacer el mercado, pagar el colegio y la salud de todos, somos mis dos hijos y yo. Mi marido trabaja en Nueva York, le ha ido bien, dice que regresará, pero no sabe cuándo;] esperamos que el dinero de sus envíos alcance para ahorrar unos pesitos y tener con qué montar un negocio. Él dice estar triste (...), nosotros también lo extrañamos, pero ahora tiene trabajo, lo que aquí nunca consiguió ([Lyda] “La menuda hace peso en la economía”, El Tiempo, 26 de abril, 2005).

Aunque este ejemplo no se refiere a la migración hacia España, permite ilustrar otro tipo de estrategia en la que las mujeres que se quedan asumen la dirección del hogar y la administración de las remesas. Dedicadas a la educación y el cuidado de los hijos, los recursos enviados son el único ingreso familiar, destinado principalmente a gastos de manutención y escolarización de los hijos. Tal como quedó demostrado en el estudio realizado en Colombia sobre la migración internacional y la utilización de las remesas (Garay y Rodríguez 2005). Esto sin dejar de lado que a pesar de la esperanza en los resultados del proyecto migratorio, este supone un precio afectivo importante para toda la familia.

"Las mujeres procedentes de América Latina (...), a su pesar, se han convertido en las nuevas empleadas de los hogares españoles" ("Echadas pa'lante", El Tiempo, 03 de diciembre, 1993). Esta frase, extracto del artículo de El Tiempo de 1993, indica que ya para la época la inserción laboral de las mujeres en España se realizaba, entre otros sectores, a través del servicio doméstico. A este respecto, la expresión "a su pesar" denota una situación de descontento, como el que se constata en los testimonios de las mujeres entrevistadas por Ofelia Restrepo en su estudio realizado entre 1992 y 1997. A través de estos se asegura que "las condiciones de marginalidad e irregularidad obligaron a las mujeres migrantes y

5 Ministerio de Asuntos Exteriores de España (2001). 
asiladas colombianas, a (...) aceptar, a pesar de su formación académica, (...) trabajos para los cuales no estaban muy preparadas" (Restrepo 2006, 75-76).

Es de resaltar que para finales de los años 1990, el servicio doméstico representaba uno de los mayores sectores proveedores de trabajo no reglamentado. El número de empleadas domésticas en Europa estaba entonces evaluado a más de un millón de personas, de las cuales la gran mayoría se encontraba en situación ilegal" (Gincel 2005, 11). La falta de papeles conlleva a la contratación en "negro" y se encuentra presente en otros sectores de inserción laboral como lo indican los siguientes testimonios.

\begin{abstract}
Sabía que mi título como tecnóloga en Administración y mis tres años de Derecho que dejaba tirados en la universidad no iban a servir para nada, pero me vine [a España]. Fui [a un bar] y luego de las dudas de la propietaria, me contrató. Hoy, tres meses después está dispuesta a darme el contrato de trabajo porque yo sigo siendo ilegal ([Mónica] "El lejano sueño español”, El Espectador, 25 de junio, 2000).
\end{abstract}

Todos dijeron que aquí necesitaban profesionales como yo, pero aún no tengo permiso de trabajo y mi título [de Ingeniera de Sistemas] no es más que papel mojado ([Eleonora] "Latinos huyen a Europa", El Tiempo, 31 de marzo, 2002).

Investigaciones recientes sobre la población colombiana en España arrojan como resultado, en cuanto al nivel de formación, que "tres cuartas partes [...] cuentan con estudios secundarios (72\%) o superiores (4\%) y de éstas no se observa una diferencia significativa por sexo, si acaso una ligera mejor formación femenina" (Vicente, Ruiz y Unzueta 2011, 73-74). Esto se ve reflejado en los testimonios anteriores, así como se revela que estos trabajos resultan ser una estrategia de supervivencia ante el no reconocimiento de sus diplomas y la falta de papeles. Fuera del desfase existente entre la formación y el empleo encontrado, está también el que estos oficios -domésticos, restauración, hotelería en el caso de las mujeres, o construcción en el caso de los hombres-son socialmente poco valorizados tanto en origen como en destino, argumento que se suma a la pérdida de estatus social con el que se enfrenta una gran parte de emigrantes en destino.

\title{
1.1 Fortaleza y espíritu emprendedor
}

La visión de mujer "echada pa'-lante" se asocia principalmente a la manera como ellas, independientemente de los obstáculos - dificultades para pagar el viaje, falta de papeles, inestabilidad laboral y separación familiar-, son capaces de salir adelante teniendo como objetivo principal, en la mayoría de los casos citados, el bienestar de sus familias. A esta imagen se aúna aquella de las mujeres asiladas. De los siete casos presentados en el artículo La condena del exilio, de El Espectador (03 de octubre, 1999), cinco corresponden a historias de mujeres periodistas, defensoras de Derechos Humanos y miembros de partidos políticos. Para algunas de ellas, al igual que las anteriores, la inserción laboral en España se hizo a través de trabajos precarios, como el caso de la periodista Fabiola Calvo "quien [...] tuvo que (...) hacer en el metro encuestas que le aseguraran el sustento" (El Espectador, 03 de octubre, 1999). La subsistencia en España se revela difícil 
a pesar de las ayudas con las que cuentan por su estatus de asiladas, esto hace que se conciba el regreso como una opción, independientemente de los riesgos que implica. Tal es el caso de Claudia Clavijo, defensora de Derechos Humanos, "esto es muy duro, yo logré un apoyo pero todo es muy costoso. Estuve a punto de regresar hace un mes pero me da miedo volver" (El Espectador, 03 de octubre, 1999). Esto pone en evidencia la complejidad del exilio y la lucha constante, entre la precariedad a la que se ven sometidas en el exterior y la imposibilidad del regreso, debido a las cuestiones de seguridad que les obligaron a salir. Otro ejemplo aparece en el artículo Asilo en España a dos lesbianas colombianas, de El Espectador (10 - 16 de septiembre, 2006), quienes después de cinco meses de amenazas por parte de los paramilitares debido a su identidad sexual y a su defensa de los derechos de la comunidad LGTB en Colombia, huyeron a España donde les acordaron el asilo por orientación sexual.

A este respecto es importante resaltar la reducción progresiva a partir de la ley de 1994, en la atribución del reconocimiento de asilo en España. Esto debido a que "se privilegia la permanencia por razones humanitarias en detrimento de la concesión de estatutos de refugiado" (De Lucas 2012, 19), poniendo en riesgo la existencia de este derecho. Situación que se suma a la dificultad que supone para los colombianos pedir el asilo, debido a que Colombia es un país con un gobierno democrático y en el que no se reconoce el estado de guerra que se vive en algunas de sus zonas (Restrepo 2006, 33).

La imagen de mujer capaz de vencer los obstáculos y salir adelante sin importar las dificultades encuentra igualmente otra representación en la figura femenina víctima de situaciones extremas. Esta corresponde a la situación que miles de personas vivieron a raíz de los atentados del $11-\mathrm{M}$ en Madrid, presentados en la prensa colombiana a través de los artículos de El Espectador Ya para qué papeles (21 de abril, 2004) y En Atocha perdí la mitad de mi vida (26 de diciembre, 2004 - 01 de enero, 2005). En el primero se describe la iniciativa del gobierno español de adjudicar la nacionalidad a todos aquellos inmigrantes víctimas del atentado y a sus familias. En el segundo se encuentra la historia de María, quien ante el dolor por la pérdida de su compañero, regresa a Colombia, y al darse cuenta de su embarazo, vuelve a España para continuar con su vida, pero tres meses después pierde su bebé.

El desarrollo de la noticia sobre el atentado se construye de manera paralela con un discurso que subraya la adquisición de la nacionalidad española como objetivo. En este contexto, el atentando acentúa el sentimiento de injusticia que se desprende del relato; es decir, María no solamente pierde "la mitad de su vida", sino que sucede justo en el momento en que estaban a punto de alcanzar la anhelada nacionalidad. En este sentido, el caso de María se convierte en el de miles de migrantes que esperan alcanzar la estabilidad administrativa y el acceso a los derechos que viene con ello, a través de la naturalización.

En el mismo artículo, su testimonio permite establecer un paralelo entre la realidad colombiana y la española que resulta paradójico, donde Colombia es sinónimo de violencia y de deshumanización por la forma en la que se identifican los cadáveres de las personas víctimas de una masacre, contrario a España que se presenta como el país de la esperanza, a pesar de reconocer que es justamente allí, que descubre lo que es ser víctima de la violencia. Sin embargo, 
esto no modifica el hecho de quedarse y rehacer su vida en España. La imagen de mujer desesperada y abatida por la doble pérdida es a su vez la de una mujer combativa, presentada como ejemplo de sobrevivencia. Esta representación de mujer fuerte y emprendedora contrasta con aquella de las mujeres presentadas bajo un ángulo de indefensión al ser víctima de la trata o el tráfico de personas y de las situaciones que se pueden derivar de su condición de irregularidad en España.

\section{Mujeres víctimas de trata y tráfico de personas}

De los temas mencionados en los siguientes titulares, la trata de personas con fines de explotación sexual es el más recurrente: En auge la trata de blancas (El Espectador, 04 de abril, 1996); Se dispara trata de blancas en Europa (El Tiempo, 13 de agosto, 1998); Trata de blancas un negocio oscuro (El Tiempo, 22 de febrero, 2000); Crecen denuncias por trata de blancas (El Tiempo, ol de agosto, 2003); Domésticas, las esclavas modernas (El Tiempo, 08 de julio, 2001); Los esclavos modernos (El Tiempo, 08 de junio, 2002); Capacitación sobre trata y migración de personas (El Tiempo, 25 de julio, 2006).

Más que artículos de investigación o crónicas, hacen eco a los informes publicados por organismos como la Organización Internacional para las Migraciones (OIM), la Organización de las Naciones Unidas contra la Droga y el Delito (UNODC), el Comité Contra la Esclavitud Moderna de la Comisión Europea, el entonces Departamento Administrativo de Seguridad (DAS), la Policía Internacional (Interpol), la Fundación Esperanza y el informe del Departamento de Estado de los Estados Unidos. Esto muestra, por un lado, el interés que despierta el tema en el ámbito internacional, así como la importancia que adquieren los resultados que transmiten, ya que sirven de punto de referencia a los dos periódicos colombianos, para presentar las cifras, los perfiles, los lugares de origen y de destino de las mujeres víctimas de este delito.

Según la información transmitida, el segundo país de destino de las mujeres tratadas es España ${ }^{6}$, y sus lugares de proveniencia en Colombia son las ciudades del Eje Cafetero, Medellín, Cali, Buga, Bogotá, Bucaramanga y los Llanos Orientales, siendo Pereira la ciudad donde más se produce este fenómeno (OIM 2006, 43). Los tratantes recurren a falsas promesas de trabajo para captar sus víctimas y una vez en destino, les retienen el pasaporte y el dinero atribuidos en origen, así como también se les advierte de la deuda que han contraído y de los modos de pago. En caso de rehusarse, las formas de presión pueden ser de orden físico - golpes, violaciones-y psicológico -amenazas contra su vida y la de sus familias en Colombia-. Varias son las publicaciones en dos periódicos colombianos: En auge la trata de blancas (El Espectador, 04 de abril, 1996); Alerta por tráfico sexual de colombianos (El Espectador, 28 de julio, 1998); Se dispara trata de blancas en Europa (El Tiempo, 13 de agosto, 1998); Aumenta la trata de mujeres (El Espectador, 29 de julio, 2000); El otro tráfico que marca el país (El Tiempo, 18 de octubre, 2000); Crecen denuncias por trata de personas (El Tiempo,

6 El principal país de destino sería Japón. 
Ol de agosto, 2003); Muertes y secuestros de colombianas en el desierto de Egipto e Israel serán investigadas (El Tiempo, 06 de septiembre, 2006).

La importancia que va tomando el fenómeno de la trata de mujeres en el país se evidencia a través del empleo de términos y expresiones como: aumento, auge, crecimiento, se dispara; y también se plasma la dimensión dramática del mismo con: alerta por tráfico, muertes y secuestros; el otro tráfico que marca el país. Cabe subrayar que Colombia era, en la época, uno de los centros más activos de reclutamiento de mujeres para la trata, precedido de Brasil y República Dominicana (Chiarotti 2003, 7-8), situación que no se ha modificado sustancialmente, a pesar de los esfuerzos realizados por el gobierno colombiano en prevención y legislación contra este delito (Ripoll 2008, 177-178). La prensa hace eco de las operaciones policiales a gran escala entre organismos de seguridad colombianos, de países de destino de la trata de mujeres y la Interpol7. Entre los operativos realizados se cita el Proyecto Gavilán, nombre que resulta de un símil en el que los tratantes son calificados de gavilanes y las mujeres víctimas, como las pequeñas aves que este consume para alimentarse. Comparación de tinte machista, presente dentro de la idiosincrasia latinoamericana, en la que las mujeres son calificadas como "pollas" o como "gallinas" en consonancia con su rol materno.

Los operativos de los organismos de seguridad son ampliamente descritos, a diferencia de las leyes en Colombia que castigan el delito. Cuatro artículos las mencionan. Dos hacen referencia a la firma de Colombia de los acuerdos internacionales de Viena y de Palermo, y los siguientes a la jurisprudencia colombiana. Las sanciones previstas en el código penal colombiano en los artículos: Los esclavos modernos (El Tiempo, 08 de junio, 2002) y Tráfico humano, horror en aumento (El Tiempo, 18 de mayo, 2003) son calificadas de "insuficientes", tras considerar que la pena impuesta no es acorde con la dimensión del delito, y de "inoperantes" debido a su incremento en el país. A pesar de estas críticas, Colombia es un país que se considera avanzado en el combate contra la trata de personas (Ripoll 2008, 182), ya que desde los años 1980, este delito se encuentra tipificado en el Código Penal (OIM 2006, 19). A partir del 2000 y gracias a la especialización de la legislación colombiana en la materia y a la iniciativa de las instituciones, se han realizado campañas de prevención y

7 Se dispara la trata de blancas (El Tiempo, 13 de agosto, 1998); Medidas contra la trata de mujeres (El Espectador, 20 de febrero, 1999).

8 En la región cafetera colombiana, una "polla" hace referencia a una mujer joven. En cuanto al símil mujer - gallina, existe igualmente una referencia en el artículo Venden amor en japonés (El Tiempo, 22 de julio, 1992) en el que el gallinero, "es como le dicen a la casa medio caída donde viven algunas mujeres". Un ejemplo claro de ello es la película mexicana de Rogelio A. González El Gavilán Pollero (1952) cuya banda original homónima, se ha convertido en un referente de la música popular en Colombia y diferentes países de América Latina.

9 Con la Ley 599 de 2000 se ampliaron las penas para este delito, pero no se modificó el tipo penal. En 2002 la Ley 747 adicionó al Código Penal (Ley 599 de 2000) la precisión sobre el tipo penal de trata de personas. Posteriormente, la Ley 985 de 2005 considera la trata de personas como un acto de movilización con fines de explotación, independientemente del consentimiento inicial dado por la víctima. También aumenta las penas de diez y quince años a trece y veintitrés años. Igualmente, adopta medidas de prevención, protección y asistencia, necesarias para garantizar el respeto de los Derechos Humanos de las víctimas y posibles víctimas de la trata de personas (OIM 2006). 
talleres de capacitación para sensibilizar a la opinión pública (Fidone et al. 2012, 31) a los que la prensa, particularmente el periódico El Tiempo, hizo un seguimiento detenido ${ }^{10}$.

\subsection{Nombrar el fenómeno de la trata y el tráfico de personas}

Existe una diferencia importante entre el discurso especializado que vehiculan los periódicos colombianos, referido a la realidad de la trata y el tráfico de personas y el uso que estos hacen de las realidades que sus fuentes, ya sea la ONU, la OIM o la Fundación Esperanza, designan. La falta de claridad en los términos o el recurso a eufemismos empleados en el discurso periodístico conducen a confusiones entre lo que es la trata, el tráfico y lo que puede derivarse de una situación relacionada con la prostitución, escondiendo así la amplitud y gravedad de dicho delito.

La confusión entre los términos podría derivarse de una falta de normativas que permitan diferenciar cada uno de los delitos; sin embargo, el uso indiscriminado de estos continúa después de la promulgación del Protocolo para prevenir y sancionar la trata de personas, especialmente mujeres y niños, que complementa la Convención de las Naciones Unidas contra la Delincuencia Organizada transnacional promulgado en el 2000 y que entró en vigor en Colombia el 13 de marzo de 2003 en virtud de la Ley 800 de 2003, que establece claramente que son dos delitos diferentes, entendida la trata de personas como:

La captación, el transporte, el traslado, la acogida o la recepción de personas, recurriendo a la amenaza o al uso de la fuerza u otras formas de coacción, al rapto, al fraude, al engaño, al abuso de poder o de una situación de vulnerabilidad o a la concesión o recepción de pagos o beneficio para obtener el consentimiento de una persona que tenga autoridad sobre otra con fines de explotación. Esa explotación incluirá, como mínimo, la explotación de la prostitución ajena u otras formas de explotación sexual, los trabajos o servicios forzados, la esclavitud o las prácticas análogas a la esclavitud, la servidumbre o la extracción de órganos (ONU 2000, 44-45).

A diferencia de la trata de personas, el tráfico no incluye una situación de explotación y se define como:

La facilitación de la entrada ilegal de una persona en un Estado parte del cual dicha persona no sea nacional o residente permanente con el fin de obtener, directa o indirectamente, un beneficio financiero u otro beneficio de orden material (ONU 2000, 57).

Otra diferencia importante a tener en cuenta es la subrayada en la legislación colombiana por el Comité Interinstitucional de Lucha contra la trata de personas (2008). Este resalta que en la modalidad del tráfico de personas, el atravesar una frontera constituye en sí un delito de cara al Estado; empero, en el caso de la

10 Iniciativas descritas en los artículos de El Tiempo: Tráfico humano horror en aumento (18 de mayo, 2003); Crecen denuncias por trata de personas, (01 de agosto, 2003), Por teléfono descubren 160 casos de trata de personas (12 de septiembre, 2004); Las trampas de la migración (09 de julio, 2005); Capacitación sobre trata y migración de personas (25 de julio, 2006). 
trata, hacia el exterior o dentro del país, hablamos de un delito contra la persona ergo de la vulneración, violación de sus derechos fundamentales, distinción que queda ausente en los artículos, al obviar las diferencias entre los dos delitos.

Por consiguiente, hablar de tráfico sexual como lo plantea el titular de El Espectador, Alerta por tráfico sexual de colombianos (28 de agosto, 1998), no permite establecer si se trata de facilitar el ingreso a un territorio determinado de un colombiano o colombiana que busca integrar la industria del sexo en un país, y menos permite deducir que se pueda tratar de un acto de explotación realizado bajo amenaza. Lo mismo, y en referencia a otro país, sucede con el titular Venden amor en japonés, de El Tiempo (22 de julio, 1992), en el que el eufemismo "vender amor" hace referencia directa a la prostitución y en ningún momento permite identificar, como sí sucede luego en el contenido del artículo, que se hará referencia a casos de trata de mujeres con fines de explotación sexual. En esta misma línea se pueden encontrar afirmaciones en otros artículos, que dan definiciones erróneas o incompletas de esta realidad que denominan "comercio de mujeres" ("salud... Pereira", El Espectador, ol de diciembre, 2002) o aún "tráfico de mujeres" ("Un círculo infernal", El Tiempo, 13 de febrero, 2003) subrayando únicamente el desplazamiento de estas. Esto sin dejar de lado la cosificación de la mujer al presentarla como una mercancía.

Otro término presente en el imaginario de la prensa es el de trata de blancas ("En auge la trata de blancas", El Espectador, 04 de abril, 1996; "Trata de blancas un negocio oscuro", $E l$ Tiempo, 22 de febrero, 2000) que tiene su origen en el siglo XIX y hace referencia al comercio y movilidad de mujeres europeas con el objetivo de explotarlas sexualmente (Keunings 2009, 17-44). Si bien puede haber un cierto parecido con lo que sucede hoy día, su utilización resulta anacrónica e inapropiada para referirse a la realidad actual mucho más matizada, de las mujeres, niños, niñas, jóvenes y hombres que son víctimas y a los métodos empleados para explotarles.

La gran mayoría de los artículos consagrados al tema presentan una visión general del fenómeno" ${ }^{11}$. España, segundo país identificado como destino de las mujeres colombianas que son tratadas (Vargas, Flórez y Mendoza 2011, 14), es mencionado en siete artículos publicados por El Tiempo; seis de estos en relación con casos de trata con fines de explotación sexual ${ }^{12}$ y uno con casos de trata con fines de explotación laboral ("Domésticas esclavas modernas", El Tiempo, 08 de julio, 2001). Igualmente se presenta como país de tránsito en el caso de una mujer tratada para blanquear dinero en bancos europeos ("Los esclavos modernos", El Tiempo, 08 de junio, 2002).

\subsection{Mujeres víctimas y discurso victimista}

A pesar de la importancia como país de destino de mujeres tratadas, solo dos artículos se interesan particularmente en España. Tenemos colombianas

Il A excepción de aquellos que hacen referencia a los casos encontrados en Japón.

12 Se dispara la trata de blancas (13 de agosto, 1998); El otro tráfico que marca al país (18 de octubre, 2000); Un círculo infernal (13 de febrero, 2003); Tráfico humano, horror en aumento (18 de mayo, 2003); Tráfico humano, un drama mundial (24 de junio, 2004); Por teléfono descubren 160 casos de trata de personas (12 de septiembre, 2004). 
jovencitas de El Espectador (07 de abril, 1999) y Tráfico humano, horror en aumento, de El Tiempo (18 de mayo, 2003). El Espectador (07 de abril, 1999) presenta las acciones realizadas por la policía española, que en los diez días anteriores a la publicación, había desarticulado "redes dedicadas al tráfico de chicas colombianas, todas dedicadas a la prostitución en moteles de carretera y la mayoría esclavizadas y engañadas por mafiosos españoles y colombianos [sic]" ("Tenemos colombianas jovencitas", El Espectador, 07 de abril, 1999). En los operativos descritos en el mismo artículo y realizados en ciudad León fueron encontradas " 40 mujeres, 28 colombianas"; en el realizado en Ciudad Real, provincia de Castilla La Mancha, considerado como el que "disparó las alertas de las autoridades" sobre el tráfico y la forma en que proceden para introducir a las mujeres de manera ilegal en España, se descubrió que doce mujeres colombianas "trabajaban desde hacía un mes en régimen de esclavitud y custodiadas por perros para que no se escaparan" ("Tenemos colombianas jovencitas", El Espectador, 07 de abril, 1999).

El tono de alarma se acentúa citando las cifras de la policía española que en 1998 "detuvo a 320 prostitutas ilegales y 125 eran colombianas". Ante esta situación, el artículo acusa al gobierno colombiano, representado en España, a través de la embajada y el consulado, de "tener poco tiempo y dinero para atender el problema" que ya en 1997 había adquirido cierta magnitud, confirmada tras el desmantelamiento de " 23 bandas en las que 50 colombianas trabajaban en lamentables condiciones". El cónsul de la época, Gabriel Fernández, define la trata como "otra forma de esclavitud", y asegura que "muchas de las mujeres han terminado en esto por necesidades económicas". Sus declaraciones dan a entender que existe conocimiento sobre el tema, mas no se habla de los mecanismos para combatirlo. Esta misma perspectiva crítica es aplicada a la prensa española, particularmente al periódico El País. Se le acusa, tanto en la introducción como en la conclusión del texto, de llenar páginas con anuncios de venta de servicios sexuales de tipo: "necesito jovencitas suramericanas, urgente"; "esclavas enmascaradas desnudas para ti", "mulatitas para esta noche". Estos anuncios aparecen como prueba que "demuestra la dimensión económica del negocio de la prostitución, el crecimiento del tráfico de mujeres en Europa y la violación de los derechos humanos de las mismas" “Tenemos colombianas jovencitas", El Espectador, 07 de abril, 1999). Si bien, a través de estos se puede constatar la variedad de propuestas de servicios sexuales en España, por el contrario no es posible aseverar que esto sea una consecuencia del aumento del tráfico de mujeres hacia Europa o que sea un hecho de violación de los derechos humanos de las mujeres u hombres que proponen dichos servicios.

Cabe anotar que así el artículo busque generar una reflexión sobre el rol que puedan tener los anuncios en un posible aumento de la trata de personas, la información suministrada contribuye a crear una amalgama entre dos cuestiones de índole diferente. Para el lector, no es posible hacer la diferencia entre la prostitución, que no es ilegal en España $a^{13} y$ ejercida con el consenti-

13 En España, la prostitución no está reglamentada en ningún sentido, no es legal pero tampoco es ilegal. No existe en el código penal sanción alguna respecto a su ejercicio. Ver Ley Orgánica 
miento de quien ofrece los servicios, a una situación de trata. Al reagrupar estas dos realidades y hacerlas converger bajo el mismo foco, se atenúa la gravedad de la trata como crimen transnacional contra la dignidad humana. A esta amalgama se aúna una nueva, que relaciona el carácter legal o ilegal de la estadía de las mujeres.

La manera en que fueron presentadas las cifras de las capturas obtenidas por la policía -320 prostitutas ilegales- permiten inferir que las mujeres fueron detenidas por ilegales, ergo pasamos de un hecho de crimen transnacional a un hecho que releva de un acto administrativo relacionado con el estatus de una persona inmigrante. Esta idea se refuerza con la frase "las colombianas deportadas son de Pereira, Cartago, Cali y ciudades de la Costa Atlántica", que se encuentra bajo un recuadro titulado "Cifras del drama". La deportación aquí sugiere una respuesta institucional de índole administrativa ante la falta de documentos de residencia y/o trabajo y no una respuesta de índole penal frente a un delito, despojando a estas mujeres de su condición de víctimas, para ser tratadas como inmigrantes sin papeles que ejercen la prostitución.

El discurso de la prensa, al evocar las razones que pueden explicar el cómo una mujer termina siendo víctima de trata, crea un perfil homogeneizador que las define. Se trata de "madres solteras", "pobres", "sin educación", empujadas por la necesidad económica y la vulnerabilidad. Perfil que se encuentra igualmente en la literatura especializada sobre el tema, pero que no puede ser utilizado como único, ya que "algunas personas desconocen su condición de víctimas, otras tantas no denuncian debido a la presión y al miedo que ejercen los tratantes sobre ellas, y finalmente a la errada tipificación por parte de la justicia de este delito" (Vargas, Flórez y Mendoza 2011, 31). Testimonios de mujeres como el de Marcela, estudiante universitaria, citado en el artículo Esclavos modernos, de El Tiempo (08 de junio, 2002) cuestionan el argumento de la falta de formación como una razón para caer en las redes de trata de personas.

\footnotetext{
Una de las colombianas que salió del Valle del Cauca el pasado enero con la ilusión de trabajar en la hostelería y fue engañada ("Tenemos colombianas jovencitas", El Espectador, 07 de abril, 1999).
}

Las convencen con engaños, como trabajar de mucamas, o las engatusan prometiéndoles ganancias rápidas para educar a sus hijos ("Un círculo infernal", El Tiempo, 13 de febrero, 2003).

La utilización de verbos como ilusionar; enredar; engañar; engatusar, empleados para describir las estrategias diseñadas por los tratantes, sugiere una cierta falta de criterio en las mujeres, que las conduce a aceptar sus propuestas. Con este discurso restan importancia a la puesta en escena de los falsos procesos de reclutamiento de los tratantes en oficinas bien situadas, con entrevistas y otras técnicas utilizadas, que pueden parecer desde todo punto de vista totalmente veraces. Por otro lado, el acentuar el deseo de adquirir dinero de manera rápida

10 de 1995 (Cortes Generales de España 1995) del Código penal español y su legislación complementaria, http://www.boe.es/legislacion/codigos/codigo.php?id=038_Codigo_Penal_y_legislacion_complementaria\&modo=1 
crea una imagen de las mujeres que las sitúa en el facilismo, en contraste con la imagen de fortaleza y emprendimiento designada a aquellas que buscan mejorar sus condiciones de vida y la de los suyos.

A esta representación de mujer pobre y engañada, se adjunta otra de mujerniña, en la que las mujeres son presentadas desde una óptica infantilizada.

Tener un empleo en el extranjero como mesera, niñera o empleada doméstica y ganar en dólares es una propuesta que deslumbra a muchas mujeres jóvenes e incautas que viajan engañadas ("Se dispara trata de blancas en Europa", El Tiempo, 13 de agosto, 1998).

Ellas se van felices esperando encontrar el paraíso y recursos para sus familias, pero desafortunadamente cuando logran escapar a esa vida que encontraron, se les vuelve a ver después de tres o seis meses en los muelles internacionales, tristes y deportadas ("El otro tráfico que marca al país", El Tiempo, 18 de octubre, 2000).

El lenguaje empleado que enfatiza la ingenuidad de las mujeres puede despertar en el lector un sentimiento de incomprensión y compasión. El primero ante la falta de malicia que per se justifica que hayan caído en esa situación y el segundo debido a las vivencias narradas en los testimonios de algunas de las víctimas.

De los artículos analizados, cinco presentan testimonios en primera persona de mujeres que han sido víctimas de trata, y solo en dos las mujeres se identifican por sus nombres.

Firmé un contrato por seis meses para trabajar en Atenas como bailarina folclórica. (...) pronto nos dimos cuenta que no bailaríamos (...). Durante tres meses trabajamos casi secuestradas y sin recibir un centavo en un bar donde además de bailar desnudas teníamos que acostarnos con los clientes. De Grecia me llevaron a Holanda. (...) descubrí que estaba embarazada. Fui obligada a abortar y yo misma tuve que pagar los 300 dólares del servicio médico. Durante el procedimiento me perforaron un intestino y me tuvieron que trasladar a un hospital ([Marta] "Se dispara la trata de blancas en Europa", El Tiempo, 13 de agosto, 1998).

Vivíamos encerradas, sin posibilidad de salir, obligadas a todo (...) los hombres que nos han traído hasta aquí soltaban los perros para que no nos moviéramos por las afueras de la casa ("Tenemos colombianas jovencitas", El Espectador, 07 de abril, 1999).

$\mathrm{El}$ anonimato al que recurren $\mathrm{u}$ obligan a estas mujeres viene en un principio debido al carácter ilegal de la trata, así como al estatus administrativo de estas mujeres en el país en el que se encuentran. A él se recurre debido al riesgo que pueden correr de ser identificadas por los tratantes y las consecuencias sociales que conlleva, ser reconocidas por personas de su entorno o el de su familia. La negación de la identidad se asocia a la pérdida de humanidad, resultado del discurso que se crea sobre las circunstancias vividas. A través de las metáforas utilizadas en los mismos testimonios de las víctimas o por parte de la prensa, se acerca las mujeres a construcciones de alteridad en las que se atribuyen aspectos o comportamientos animalizados. 
Si tenemos en cuenta la importancia del lenguaje como base para establecer, expresar y provocar emociones, la prensa tiene un rol a efectos conductuales. A través de ejemplificaciones que trascienden el discurso, puede ilustrar y prevenir para que otras mujeres no caigan en las falsas propuestas de estas redes. Sin embargo, insistir en el encadenamiento de hechos dramáticos, como en el caso de Marta, construye un discurso de marginalidad en torno a estas mujeres que desvirtúa su capacidad de agencia y se aúna a la imagen ya establecida de mujeres pobres, engañadas e infantilizadas.

\section{Representaciones familiares y de género}

Desde otro registro, la prensa presenta a las mujeres a través de un rol materno que les es designado. En una sociedad como la colombiana, donde la familia tiene un rol social importante, los valores y las funciones tradicionales que se siguen imponiendo a la mujer tienen mucho peso social, por ser ella la gestora y paridora de los hijos (Restrepo 2006). Partimos de esta constatación sin dejar de lado que la migración modifica la familia, reconfigurándola y estableciendo otros roles y comportamientos a los que cada miembro debe adaptarse. Este nuevo funcionamiento conduce a situaciones objeto de estudio y de análisis desde la academia, y de información desde el periódico El Tiempo: La crisis divide a las familias (19 de noviembre, 1999); Los problemas de los hijos del éxodo (16 de junio, 2004); Remesas pueden golpear familias (04 de diciembre, 2005); Migración de risaraldenses está creando generación de "huérfanos con padres vivos" (03 de septiembre, 2006); Éxodo desintegra a las familias de Risaralda (04 de septiembre, 2006); Pensionados a los 15 años (03 de noviembre, 2006).

El enfoque dado desde los titulares responsabiliza a la migración de la crisis de las familias, y realza el impacto negativo que tiene en ellas la salida de las cabezas de hogar y el envío de las remesas, particularmente en los hijos considerados huérfanos o aun pensionados.

\footnotetext{
De esas personas [que se quedan] y sus sentimientos no se habla. Como si fueran más importantes las maromas que tendrán que hacer los que se van para sobrevivir que la separación física y la ruptura emocional a la que se están enfrentando las familias colombianas ("La crisis divide a las familias", El Tiempo, 19 de noviembre, 1999).
}

Habría que estudiar los efectos de la migración sobre la desintegración familiar, la violencia doméstica, la violencia social y la seguridad de los ciudadanos. Seguramente, la economía del país recibe menos recursos por remesas que los que está invirtiendo o va a invertir hacia el futuro (...) para atender hechos de violencia producidos por hijos que no cuentan con la autoridad de sus padres ("Pensionados a los 15 años", El Tiempo, 03 de noviembre, 2006).

En el primer artículo, la migración supone una ruptura tanto física como emocional enfocada desde los que se quedan, invisibles, ante un discurso principalmente dedicado a los que emigran. En el segundo, la migración al desarticular la familia, núcleo de la sociedad, contribuye al aumento de la violencia en el país y socava la poco "sólida estructura familiar colombiana, golpeada por el auge de los divorcios en los años 80" ("Pensionados a los 15 años", El Tiempo, 
03 de noviembre, 2006). Este argumento no toma en cuenta que ya "en los años sesenta los cambios políticos, sociales, religiosos y culturales en Colombia trajeron consigo factores de transformación que condujeron al surgimiento de nuevas formas alternas de familia" (Restrepo 2006, 52-53). Esto no significa que la estructura de la familia colombiana se haya debilitado; por el contrario, es una muestra de que la familia no es una unidad rígida y modélica, tal como se concibe desde una visión tradicional. Insistir en esta tesis es desconocer que esta "forma de familia ha decrecido, al mismo tiempo que otras formas, como la monoparental, la extensa" (Puyana 2007, 267) o aún aquella donde existen padres o madres del mismo sexo, han ido fortaleciéndose.

Continuando con la visión migración-ruptura, el artículo El dólar de los pobres insiste en que la migración "implica el rompimiento de núcleos familiares, toda vez que los individuos cabeza de familia viajan para vender su mano de obra" (El Espectador, 18 de noviembre, 2001). Al desconocerla como un proyecto colectivo, la migración resulta entonces de una decisión unipersonal, instrumentalizada desde una perspectiva de lógica de mercado.

\footnotetext{
Para la psicóloga María Elena López ha llegado el momento de que quienes están saliendo del país tomen un tiempo entre la venta de sus objetos personales y la pedida de visas para reflexionar sobre el paso que van a dar y, sobre todo, para permitirles a los que los rodean hacer el duelo respectivo por la pérdida que van a tener. (...) la mayoría de la gente decide de manera inconsciente dedicar todo su tiempo a los papeles y los arreglos ("La crisis divide a las familias", El Tiempo, 19 de noviembre, 1999).

\begin{abstract}
Una generación de miles de niños y jóvenes (...) está creciendo en Risaralda lejos de sus padres, que se fueron a buscar mejor futuro a Europa o Norteamérica, y los dejaron con familiares o amigos ("Los problemas de los hijos del éxodo", El Tiempo, 16 de junio, 2004).

Papás, mamás, piensen bien porque se van a ganar dinero y cuando vuelven ya no tienen hijos (...) podemos llamar a estos niños, huérfanos con padres vivos", dice el sacerdote Acosta ("Migración de risaraldenses está creando generación de "huérfanos con padres vivos", El Tiempo, 03 de septiembre, 2006).
\end{abstract}

Los artículos que establecen el vínculo entre migración y familia, como lo indican los extractos ut supra, subrayan los efectos negativos de la migración y su relación con las problemáticas que esta puede generar dentro de la familia. Entre ellos el abandono al que se ven sometidos los hijos, referido a través de verbos como "dejar" o adjetivos como "huérfanos" y el sufrimiento de los que se quedan generado por un proyecto que se supone poco dimensionado y egoísta. Insistir recurrentemente en este aspecto negativo transforma el argumento en evidencia que se convierte en verdad. Más aún si tenemos en cuenta que en la sociedad contemporánea, "los medios de comunicación constituyen un criterio importante de lo que es evidente" (Van Dijk 2003, 67). Por consiguiente, para una persona que no tiene un referente directo con el hecho migratorio, la migración desintegra familias y podrá sustentarlo por medio de la información adquirida en el periódico, dejando de lado testimonios positivos, como los que citamos a continuación, tras considerarlos, en términos factuales como una excepción a la regla. 
La platica me alcanza para hacer el mercado, pagar el colegio y la salud de todos,
somos mis dos hijos y yo. Mi marido (...) trabaja en Nueva York, le ha ido bien,
dice que regresará, pero no sabe cuándo, (...) esperamos que el dinero de sus en-
víos alcance para ahorrar unos pesitos y así tener con qué montar un negocio. (...)
-Gracias a Dios- ahora tiene trabajo, lo que aquí nunca consiguió ("La menuda hace
peso en la economía", El Tiempo, 26 de abril, 2005).

Hasta sus 45 años, Rocío (...) cocinó para trabajadores en fincas cafeteras donde su esposo, (...) era mayordomo. Para ella y sus siete hijas fueron años de privaciones. A la muerte de él (...), la situación se agravó. Por eso dos de sus hijas se fueron a España en los últimos cuatro años y luego el esposo de otra (...). Hoy, Rocío cuida tres nietos, para lo que le giran casi dos millones de pesos mensuales, y sus hijas disfrutan de comodidades que no tuvieron de niñas ("Arrancó censo de migración y remesas", El Tiempo, 03 de agosto, 2004).

En estos casos, se identifica la estrategia de reconfiguración de roles dentro de la familia que implica la migración de uno de sus miembros. En el primero, siendo el esposo el emigrante, la mujer asume la jefatura del hogar; en el segundo se trata de una familia extensa en la que la abuela asume el rol de cuidadora de los nietos, mientras sus hijas trabajan en España. Por otro lado, resaltan la importancia que tiene el encontrar un buen trabajo, en el mejoramiento de las condiciones de vida de todos los miembros de la familia. Aunque reconocen que no es fácil desde el punto de vista afectivo, hacen hincapié en que la decisión se ha tomado ante la imposibilidad de encontrar en Colombia un empleo que contribuya a satisfacer sus necesidades. Resulta de interés recordar que estos dos testimonios son extractos de artículos, cuyo tema principal es el impacto de las remesas en las familias. Si tenemos en cuenta que en esta época las remesas se ven como una cuestión positiva, es posible que los testimonios que se hayan escogido para los artículos lo sean igualmente. Esto supondría entonces que la visión de la migración y las familias varía según el tema desde el cual se aborde. Si se hace desde el punto de vista únicamente familiar se asume como experiencia negativa y si esta se inserta en una realidad general sobre las ventajas que pueden representar las remesas, será entonces una visión positiva ergo una buena salida para mejorar las condiciones económicas de las familias y disminuir la pobreza en Colombia.

La tendencia en los periódicos es ver la cuestión migración-familia desde las consecuencias en los hijos que se quedan en origen. Los artículos se concentran en ejemplos de niños y jóvenes en Risaralda debido a la importancia de la emigración en el departamento. Según sondeos realizados "en solo dos colegios públicos de la ciudad [de Pereira], se encontraron 100 niños que tienen alguno de sus padres en el exterior (...) [Hecho que] prendió las alarmas del Instituto Colombiano de Bienestar Familiar (ICBF) en Pereira, de la Fundación América España-Cooperación (Aesco)" "Los problemas de los hijos del éxodo", El Tiempo, 16 de junio, 2004) y del gobierno local. Ante estos resultados, Aesco lanzó el programa "Hablando con mamá" para que los niños puedan comunicarse con sus padres en España por videoconferencia y el gobierno local creó un Centro de Orientación para jóvenes con padres ausentes, dirigido a todos los integrantes del núcleo familiar y descrito a través del artículo Migración de risaraldenses está 
creando generación de "huérfanos con padres vivos" (El Tiempo, 03 de septiembre, 2006).

Más allá de las iniciativas que puedan emprenderse para acompañar a estos niños y jóvenes, la imagen social que se crea a través de los medios y de los términos que se emplean para designarles les redefinen. Expresiones como hijos del éxodo; huérfanos con padres vivos o pensionados a los 15 años, desnaturalizan el lazo familiar que tienen con los padres o madres que han emigrado, al denominarlos "éxodo" o incluso lo anihila utilizando el término "huérfanos". Nociones acompañadas de una en la que la relación está mediada por el dinero, comparando la vida de un joven de 15 años que vive de las remesas que le envían sus padres, con la vida de una persona jubilada.

Los jóvenes de 15 años y menos, dejan de estudiar o de realizar alguna labor productiva y lo único que hacen es esperar todos los meses las remesas que les mandan sus padres [...] se están vinculando a actividades violentas y delictivas ("Pensionados a los 15 años", El Tiempo, 03 de noviembre, 2006).

Los niños no practican actos elementales como tender su cama y se llega a casos de niños de 12 años que fuman, ingieren licor o sufren depresiones que los llevan a intentar suicidio ("Migración de risaraldenses está creando generación de 'huérfanos con padres vivos"', El Tiempo, 03 de septiembre, 2006).

Uno de los costos más altos que ha generado esta migración es el de familias transnacionales, lo que ha conllevado a que haya jefes de hogar menores de 20 años porque en muchos casos viajan los dos padres y los hijos quedan a cargo del hermano mayor ("Remesas se están volviendo sustituto de empleo en el país", El Tiempo, 06 de julio, 2005).

La ausencia de los padres, como aquí se presenta, empuja a los jóvenes hacia actitudes de riesgo, como son el consumo de tabaco, de alcohol o aun de acceso a "programas de videos que traen unos mensajes de ganarse la vida rápida y fácilmente" ("Remesas pueden golpear familias", El Tiempo, 04 de diciembre, 2005). Los jóvenes resultan ser personas desestructuradas sin principio moral o social, que aprovechan las remesas para mantener sus actividades delictivas y de ocio. Paralelamente a esta imagen, surge aquella en la que aparecen como cabezas de familia, bajo la óptica de un rol impuesto por la salida de los padres. De esta forma se le atribuye a la familia "la raíz de los problemas sociales y se justifica reducir las funciones del Estado hacia sus necesidades, culpabilizándola de los problemas de las nuevas generaciones" (Puyana 2007, 268).

Los abuelos muchas veces no pueden ejercer la disciplina, los niños no practican actos elementales (...) o caen en excesos en busca de afecto. Hace poco una abuela tuvo que pagar 2,8 millones de pesos en llamadas al exterior porque los niños se dedicaron a llamar". Para Diana, (...) el manejo de tres de sus nietos es un dolor de cabeza. Hace cinco años, cuando una de sus hijas partió con el esposo a España, ella asumió el cuidado del nieto mayor (...). Otra hija suya acogió los otros dos niños de la pareja ausente, pero al año se rindió por los disgustos que le ocasionaban y los dejó al cuidado de otra tía. Después llegaron donde una tercera. Ahora cada niño está en casas diferentes ("Migración de risaraldenses está creando generación de 'huérfanos con padres vivos", El Tiempo, 03 de septiembre, 2006). 
La explicación a los comportamientos antes citados de los jóvenes, no solo se encuentra en la salida de los padres, sino también en la incapacidad de las personas que se quedan a su cargo, principalmente las abuelas, de ejercer alguna autoridad sobre ellos. Sin embargo, el hecho de que el conflicto con los jóvenes se presente únicamente desde el ángulo de la migración, deja de lado, no se sugiere o al menos no se expone "que los vínculos previos a la migración, como también el proceso a través del cual se resignifican dichos vínculos entre otros aspectos, determinan el curso que estos procesos adoptan y los significados que les otorgan las personas implicadas" (Rivas y Gonzálvez 2009, 93). Es decir, que puede que existan casos en los que las relaciones ya sufrían un cierto deterioro dentro de la familia, y que no necesariamente obedecen a problemas generados por la migración en sí, aunque influya.

\subsection{Responsables de la familia - abandono de la familia}

Por personas cabezas de hogar se entiende en general en la prensa, al padre o la madre del núcleo familiar. Empero, las referencias que hasta aquí eran genéricas se tornarán prioritariamente hacia la figura materna.

En el estudio (...) identificamos un barrio en el que los niños se quedan sin una estructura, porque sus madres no están para darles la disciplina (entrevista a la canciller Carolina Barco, "Remesas pueden golpear familias", El Tiempo, 14 de febrero, 2005).

El eje cafetero y el Valle generan los mayores flujos migratorios a España y buena parte son mujeres. Dejan en muchos casos al esposo. Se tarda unos tres o cuatro años para la reagrupación familiar y en ese tiempo la relación se deteriora. Hay mucha desarticulación de colombianos migrantes (...) 14,45\% de las mujeres del Eje Cafetero, que son potenciales migrantes, tienen hijos, según un estudio de Aesco Colombia (...), en la mayoría de los casos son mujeres cabeza de hogar. De acuerdo con el mismo estudio, del total de mujeres que quieren irse del país, $49 \%$ están casadas o en unión libre ("Migración de risaraldenses está creando generación de 'huérfanos con padres vivos"', El Tiempo, 03 de septiembre, 2006).

Siguiendo el razonamiento que se va creando en la prensa, si la mayoría de las personas que emigran del país son mujeres, ergo es debido a su salida que la familia se está desestructurando. Su ausencia genera la falta de disciplina en los hijos, e igualmente el deterioro de la relación con el cónyuge. Situación que a futuro no parece mejorar, si tenemos en cuenta las cifras citadas ut supra que ilustran la voluntad de emigrar de las mujeres entrevistadas, independientemente de su situación familiar. Frente a esta realidad, los artículos no se cuestionan, o no mencionan expresamente el rol de los hombres como responsables del hogar en un proyecto familiar como es la migración, "donde se resignifican las cotidianidades y las relaciones familiares" (Rivas y Gonzálvez 2009, 92). Un ejemplo de ello, son los siguientes casos evocados por el periódico El Tiempo.

Erika nunca ha visto a su mamá, (...) solo conoce su voz por teléfono. Hace unos días, cuando Gladis le preguntó qué quería al cumplir 6 años respondió: Que vengas para conocerte. Cuando ella se marchó a España, la pequeña apenas tenía unos meses y su padre nunca la reconoció. Desde entonces (...) está al cuidado de la abuela 
y de una tía. Aunque no le falta nada, (...) se siente triste y sola. A veces llora al ver a sus primos jugar con sus papás, o cuando en el kínder le preguntan por qué los suyos no la van a recoger.

John vive con su abuela (...), no tiene papá porque fue asesinado hace cinco y su mamá (...) se fue a vivir a España poco antes de la muerte. En este tiempo, el muchacho ha perdido dos años en el colegio y son frecuentes los llamados de atención por su conducta agresiva. "Yo no le importo a nadie, ni siquiera a mi mamá ("Los problemas de los hijos del éxodo”, El Tiempo, 16 de junio, 2004).

El enfoque dado aquí desde la perspectiva de los hijos y el sufrimiento que viven sitúa la responsabilidad en las madres que emigraron, mas no da lugar a un análisis de la situación familiar en sí o a la responsabilidad de la pareja que se queda en Colombia. Esta falta de cuestionamiento del rol paterno se aúna a la percepción existente en el ideario colectivo colombiano, en el que a diferencia del rol materno, el paterno puede asumirlo cualquiera. Este argumento es avanzado en un artículo referido a los problemas de los jóvenes hijos de emigrantes, para situar la necesidad de la presencia de los dos referentes parentales en la educación de los hijos. Sin embargo, se utiliza el ejemplo de los jóvenes en las comunas de Medellín y Cali, dos situaciones que obedecen a realidades sociales diferentes, para asegurar que "odian la figura masculina. Sicarios para los que ser hombre no significa nada. Para ellos papá puede ser cualquiera, pero la mamá es sagrada" "Migración de risaraldenses está creando generación de "huérfanos con padres vivos", El Tiempo, 03 de septiembre, 2006). Esto demuestra, por un lado, que existen casos en los que los jóvenes pueden asumir prácticas delictivas aun teniendo a sus padres cerca y, por otro, que la concepción de familia en Colombia y el funcionamiento de la misma obedecen a cuestiones estructurales en las que existe un rechazo particular a la figura paterna con respecto a la materna que es considerada fundamental. Desde esta perspectiva, se concibe a la mujer como única garante de la unidad familiar, lo que explica que su accionar sea mucho más criticado que el del hombre. La mujer se perfila así como alguien indispensable para la crianza y el crecimiento de los hijos, dejando de lado la responsabilidad compartida que esto implica.

\section{Conclusiones}

A pesar de la magnitud que adquiere la migración colombiana en la época, pocos son los artículos que le son consagrados. Los conceptos transmitidos por las investigaciones al respecto o por los expertos consultados no son utilizados claramente, lo que conduce a confusiones importantes en cuanto a las realidades a las que hacen referencia. En este contexto y así se reconozca la feminización de los flujos migratorios, en el universo lexical creado en torno a la emigración predomina el genérico masculino que oculta la verdadera dimensión del rol de las mujeres como protagonistas y portavoces del proyecto migratorio.

Dentro de las representaciones culturales que les son atribuidas, aquella que se refiere positivamente a su capacidad de emprendimiento resulta minoritaria frente a clichés establecidos, en los que son responsables de la desestructuración familiar y, por extensión, de los problemas sociales que causan sus hijos al 
sentirse abandonados. Esto sin dejar de lado las referencias que reenvían a una concepción de mercancía humana disponible en el mercado, mujeres incautas, prostitutas, con falta de agencia para evitar ser presas de las redes de la trata o del tráfico, o aun víctimas invisibles detrás de denominaciones como inmigrantes o ilegales.

A partir de ello constatamos que el discurso de alteridad construido en los periódicos El Tiempo y El Espectador, en torno a las mujeres migrantes colombianas hacia España, se centra más en los aspectos negativos que a ellas se asocian, creando representaciones culturales que inducen a prácticas sociales discriminatorias de subalternidad (Van Dijk 2000).

Quedan por analizar los discursos existentes en la prensa española, para así establecer los puntos comunes o divergentes, entre la visión que se crea en los dos países en torno a las migrantes colombianas. Así como la capacidad de resonancia que pueden tener discursos alternativos en los dos países, que conduzcan a la reinversión de la imagen de subalternidad femenina predominante.

\section{Referencias bibliográficas}

\section{Fuentes primarias}

Congreso de la República de Colombia. Ley 599 de 2000. Diario Oficial No. 44.097, 2000, http://www.alcaldiabogota.gov.co/sisjur/normas/Normal.jsp?i=6388 (último acceso: 13 de marzo de 2015).

Congreso de la República de Colombia. Ley 747 de 2002. Diario Oficial No. 44.877, 2002, http://www.alcaldiabogota.gov.co/sisjur/normas/Normal.jsp?i=6881 (último acceso: 13 de marzo de 2015).

Congreso de la República de Colombia. Ley 985 de 2005. Bogotá, 26 de agosto de 2005, http://historico.presidencia.gov.co/leyes/2005/agosto/ley985260805.pdf (último acceso: 13 de marzo de 2015).

Congreso de la República de Colombia. Ley 800 de 2003. Diario Oficial No. 45.131, 2003, http://www.alcaldiabogota.gov.co/sisjur/normas/Normal.jsp?i=15011 (último acceso: 13 de marzo de 2015).

Cortes Generales de España. Ley Orgánica 10 de 1995 del Código penal. Boletín Oficial del Estado (BOE) No. 281, 1995, http://www.boe.es/buscar/act.php?id=BOEA-1995-25444 (último acceso: 15 de marzo de 2015).

Ministerio de Asuntos Exteriores de España. Acuerdo entre España y Colombia relativo a la regulación y ordenación de los flujos migratorios laborales. Boletín Oficial del Estado (BOE) No. 159, 2001, http://www.boe.es/diario_boe/txt. php?id=BOE-A-2001-12853 (último acceso: 15 de marzo de 2015).

Periódico El Tiempo, 1990-2006 (impreso y digital).

Periódico El Espectador, 1990-2006 (impreso).

\section{Fuentes secundarias}

Aparicio, Rosa y Carlos Giménez (dir.). Migración colombiana en España. Ginebra: OIM, 2003.

Chiarotti, Susana. «La trata de mujeres: sus conexiones y desconexiones con la migración y los derechos humanos». Serie Población y Desarrollo, $n^{\circ} 39,2003$ : $1-31$. 
Comité Interinstitucional de lucha en contra de la trata de personas. Estrategia Nacional Integral de lucha contra la trata de personas. Bogotá, 2008. http:// scm.oas.org/pdfs/2010/CIM02770T-Ei.pdf (último acceso: 13 de marzo de 2015).

De Lucas, Javier. «Políticas públicas, inmigración, asilo». En Los retos de las políticas públicas en una democracia avanzada, de varios autores. Vitoria-Gasteiz: Ararteko, 2012: 1-27.

Departamento Administrativo Nacional de Estadísticas (DANE). Censo general 2005. Bogotá: DANE, 2008 http://www.dane.gov.co (último acceso: 13 de marzo de 2015).

Fidone, Bianca, Betty Pedraza, Aura Londoño, Alejandra Suarez, Eydis Murillo, Carolina Sánchez, Nancy Alarcón y Ángela Cortés. Estado del arte: la prevención de la trata de personas en Colombia. Bogotá: Corporación Espacios de Mujer, Corporación Amiga Joven y Red Tamar, 2012.

Garay, Luís y María Medina. La migración colombiana a España, el capítulo más reciente de una historia compartida. Madrid: Ministerio de trabajo e inmigración, 2007.

Garay, Luís y Adriana Rodríguez. Estudio sobre migración internacional y remesas en Colombia. Bogotá: Ministerio de Relaciones Exteriores, OIM, 2005, vols. I, II, III.

Gincel, Anne. «L'immigration des femmes colombiennes en France: pour quelle mobilité?». Ponencia presentada en Mobilités au féminin, Tanger, 15-19 de noviembre de 2005, 1-24. http://rajfire.free.fr/IMG/pdf/immigration_femmes_ colombiennes_france.pdf (último acceso: 29 de octubre de 2014).

Guarnizo, Luis. Londres latina: la presencia colombiana en la capital británica. México D.F.: Universidad Autónoma de Zacatecas, 2008.

Keunings, Luc. «L'affaire de la traite de blanches un aspect de la prostitution urbaine en Europe Occidentale au XIXe siècle». En Du sordide au mythe, l'affaire de la traite de blanches (Bruxelles, 1880), dirigido por Jean Chaumont y Christine Machiels, 17-44. Bruselas: Presse Universitaire de Louvain, 2009.

Nash, Mary. Inmigrantes en nuestro espejo. Barcelona: Icaria, 2005.

Observatorio de Medios. La credibilidad de los medios de comunicación en Colombia, segunda medición. Bogotá: Universidad de la Sabana, 2009.

Organización Internacional para las Migraciones (OIM). Dimensiones de la trata de personas en Colombia. Bogotá: OIM, 2006.

Organización de las Naciones Unidas (ONU). Convención de las Naciones Unidas contra la delincuencia organizada transnacional y sus protocolos. Nueva York: ONU 2004.

Puyana, Yolanda. «El familismo: una crítica desde la perspectiva de género y el feminismo». En Familias, cambios y estrategias, editado por Yolanda Puyana y María Ramírez, 262-278. Bogotá: Departamento de Trabajo Social, Universidad Nacional de Colombia, Colección CES, 2007.

Restrepo, Ofelia. Mujeres colombianas en España. Historias, migración y refugio. Bogotá: Editorial Universidad Pontificia Javeriana, 2006.

Rivas, Ana y Herminia Gonzálvez (eds.). Familias transnacionales colombianas: transformaciones y permanencias en las relaciones familiares y de género. Madrid: Editorial Catarata, 2009. 
Ripoll, Alejandra. «Colombia: semillero para la trata de personas». Revista de Relaciones internacionales, estrategia y seguridad, Vol. 3, $\mathrm{n}^{\circ} 1$ (enero-junio 2008): 175-186.

Sanchis, Enric. «Trabajo no remunerado y trabajo negro en España». Papers: Revista de Sociología, $\mathrm{n}^{\circ}$ 75, 2005: 85-116.

Solé, Carlota y Sonia Parella. «Mujeres inmigrantes no comunitarias en el mercado de trabajo español». En Hispanos en Estados Unidos, inmigrantes en España: ¿Amenaza o nueva civilización?, editado por Tomás Calvo, 55-82. Madrid: Catarata, 2006.

Van Dijk, Teun. El discurso como interacción social. Barcelona: Gedisa, 2000.

Van Dijk, Teun. Ideología y discurso. Barcelona: Ariel lingüística, 2003.

Vargas, Elvia, Carmen Flórez y Laura Mendoza. Trata de personas en Colombia: una aproximación a la magnitud y comprensión del problema. Bogotá: OIM, Universidad de los Andes, 2011.

Vicente, Trinidad, Andrea Ruíz y Amaya Unzueta. Remesas, género y desarrollo: las migraciones colombianas en el País Vasco. Bilbao: Editorial Bakeaz, 2011. 